Article

\title{
Improvement of Transient State Response through Feedforward Compensation Method of AC/DC Power Conversion System (PCS) Based on Space Vector Pulse Width Modulation (SVPWM)
}

\author{
Seok-Jin Hong ${ }^{1}{ }^{\circledR}$, Seung-Wook Hyun ${ }^{1}$, Kyung-Min Kang ${ }^{1}$, Jung-Hyo Lee ${ }^{2}$ \\ and Chung-Yuen Won ${ }^{1, *}$ \\ 1 Information and Communication Engineering, Sungkyunkwan University, Suwon 16419, Korea; \\ gujjim@naver.com (S.-J.H.); hahama19@hanmail.net (S.-W.H.); innovate_k@naver.com (K.-M.K.) \\ 2 Department of Electrical Engineering, Kunsan National University, Gunsan, Jeollabuk-do 54150, Korea; \\ jhlee82@kunsan.ac.kr \\ * Correspondence: woncy@skku.edu; Tel.: +82-31-290-7169
}

Received: 30 April 2018; Accepted: 3 June 2018; Published: 6 June 2018

\begin{abstract}
In a DC distribution system configured by AC/DC power conversion system (PCS), the voltage control performance of the AC/DC PCS determines the stability and reliability of the DC distribution grid. The DC voltage of grid is maintained by capacitor, thus transient voltage is an inevitable problem when a grid is connected with a high amount of load or renewable energy. Space vector pulse width modulation (SVPWM) is well known as a stable modulation method and is used in AC/DC PCS and many types of topologies, but a solution for the transient states issue of DC link has not clearly been studied. In this paper, a feedforward compensation method based on the mathematical model of SVPWM is proposed to solve the transient state problem in a DC distribution system. The proposed method is verified by simulation and experiment. AC/DC PCS with the proposed feedforward compensation method has more robust DC voltage control characteristics.
\end{abstract}

Keywords: feedforward compensation; space vector pulse width modulation (SVPWM); robust DC grid; DC distribution; transient state response; improved response

\section{Introduction}

As the fields of power semiconductor technology and power converter technology have advanced and interest in environmental pollution has increased, a distributed power source utilizing new and renewable energy has been attracting attention, and DC distribution has been actively studied for this purpose. DC distribution can be effectively connected to renewable energy sources and it can form an efficient power grid [1-3]. Therefore, it is being applied in many applications, such as smart grids, internet data center (IDC), commercial buildings, and etc. [4-6]. The DC distribution is configured as shown in Figure 1. Loads connected to the DC distribution are mostly nonlinear electronic loads such as lighting, computers, energy storage systems (ESS), and variable speed driving inverters for air conditioners, and these loads are sensitive to voltage fluctuations in the DC distribution [7-9].

Because AC/DC power conversion system (PCS) are essential in maintaining the existing AC system and constructing a separate DC distribution, research into how to apply various topologies in various fields has already been conducted $[10,11]$. The three-phase AC/DC PCS is particularly advantageous in that the power factor is controllable and that the power flow is bidirectional when compared to a diode rectifier. Therefore, AC/DC PCS is adopted in applications where less distortion is required in the $\mathrm{AC}$ current waveform in order to meet the stringent regulations for the electrical 
harmonic quality of the AC system. Since the AC/DC PCS can control not only the magnitude of the current, but also the phase, the power factor can be controlled through the phase information of the AC system. Moreover, the DC link voltage can be controlled by controlling the input power [12,13].

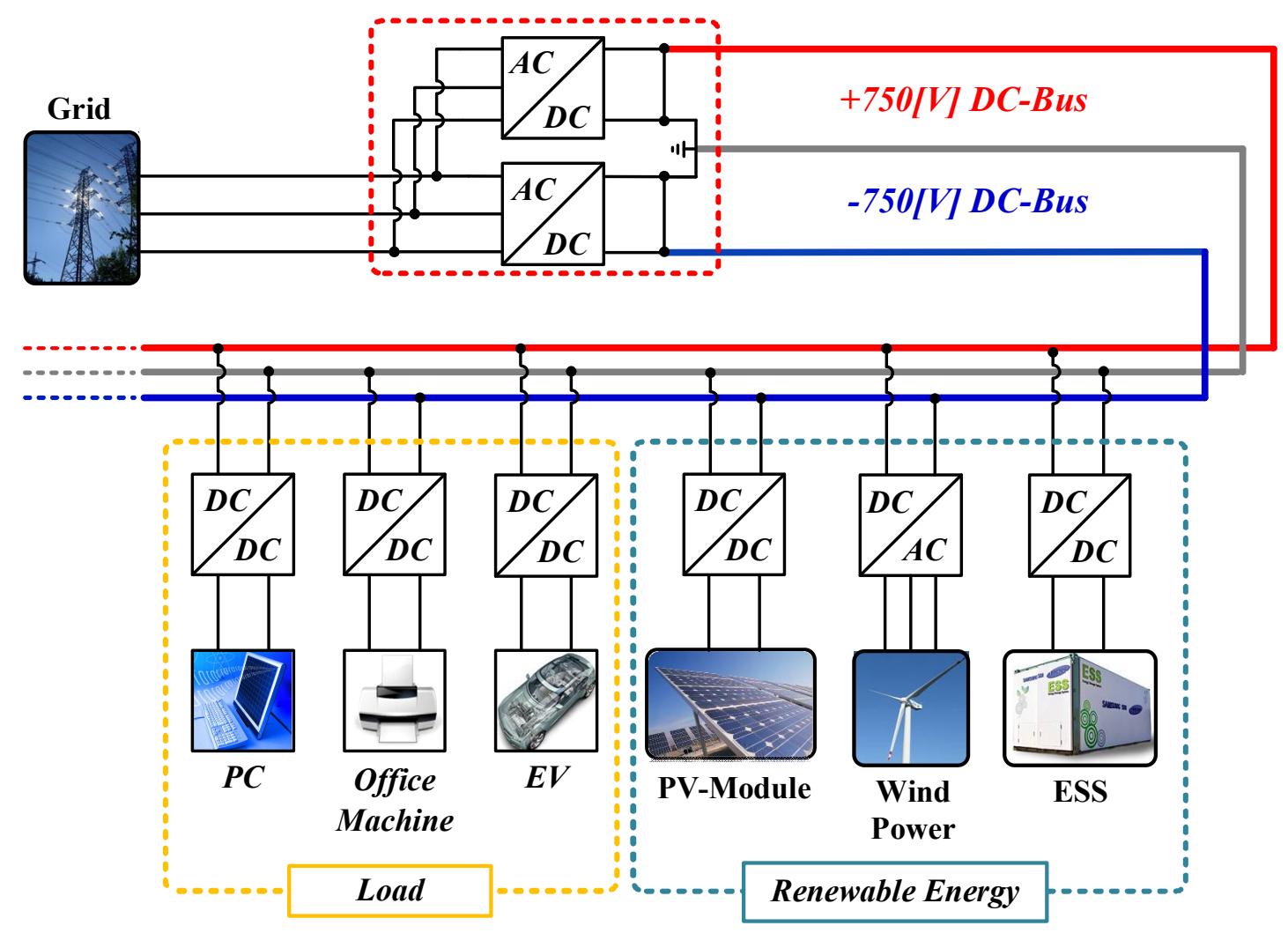

Figure 1. Configuration of DC distribution.

Generally, space vector pulse width modulation (SVPWM) is applied to generate a switching signal in AC/DC PCS applying voltage oriented control (VOC) [14-16]. In SVPWM, the maximum magnitude of the voltage that each vector can output varies in proportion to the voltage of the DC link (DC distribution voltage in this case). Therefore, if the DC link voltage fluctuates, the magnitude of the output voltage fluctuates as well. This is particularly true in a DC distribution system that is constructed using AC/DC PCS where the load is centralized, and power is generated/stopped from various renewable energy sources or nonlinear load is frequently connected/disconnected. This also causes a transient state of the DC distribution voltage, which refers to a fluctuation of the DC link voltage of the AC/DC converter. Also, DC-link voltage can be changed by AC voltage and current dips [17-21]. A robust DC voltage control characteristic of AC/DC PCS is required to supply power to the sensitive load (to voltage fluctuation) that is connected to the DC distribution in a stable manner.

There have been several studies regarding the robust DC voltage control characteristics [22-24]. In regards to robust DC distribution voltage, the method of applying Droop Control to all power converters connected to a DC distribution was studied in [25-28]. However, voltage ripple according to the droop curve always appears in voltage control of a DC distribution using droop control, and strict regulation is necessary for applying the droop curve for every device that is connected to the DC distribution. Therefore, a study was conducted to improve the robustness of droop control using model predictive control in [29]. However, a complex control loop must be constructed to improve the control performance in order to implement the control method proposed in [29]. It is also impossible to predict and model all of the loads connected to the DC grid in terms of maintaining power and the supply of power. 
Therefore, the most reliable way to increase the robustness and dynamics characteristic of DC distribution is to improve the performance of AC/DC PCS and feedforward compensated to the output through the value that was obtained through modeling of the AC/DC PCS system [30].

Meanwhile, a control method for voltage stabilization of the DC link voltage is studied in [19-21] when voltage dips occur on the AC side voltage. The control method of improving control performance by adding a feedforward compensation term to the $d-q$ axis current controller was applied in $[20,21]$. In this method, however, AC that was connected to PCS cannot control the Power Factor of the AC side clearly.

In this paper, a feed forward compensation method is proposed for robust DC voltage control characteristic of AC/DC PCS configuring the DC distribution network. The system applying the proposed compensation method improved control performance not only in the transient state occurring in the DC grid, but also in the AC voltage dip. The configuration of the DC distribution is reviewed and SVPWM is analyzed to propose compensation method for improving the DC-link voltage control for applying the proposed method. The DC distribution system that is applied in the proposed compensation method is modeled and compared with the conventional DC distribution system model in terms of stability. Moreover, simulation and experimentation were carried out to verify the validity of the proposed method.

\section{Feedforward Compensation Method for Transient State Output Voltage}

The circuit diagram of the DC distribution system that is used in this paper is shown in Figure 2. The overall system consists of a bidirectional two-level AC/DC PCS module in series. Each module is configured with an initial charge circuit, LCL filter. The output voltage of each module is $750 \mathrm{~V}_{\mathrm{dc}}$ and the total voltage is $1500 \mathrm{~V}_{\mathrm{dc}}$. The initial charging circuit of each module was applied to limit the inrush current, which can cause damages of the IGBT and the output capacitor due to the low impedance of the DC link capacitor at startup. The resistance $\left(R_{\text {pre }}\right)$ that is applied to the initial charging circuit was designed by the RC time constant with the DC link capacitor. The LCL filter has a smaller volume and inductance value than the L filter and the LC filter, also having a large harmonic attenuation effect. It is designed according to the considerations of system capacity, impedance, switching frequency, filter cut-off frequency, etc. As a tertiary passive filter, resonance may occur between the elements of the filter at specific frequencies on the LCL filter. In order to minimize this resonance, many studies have been conducted, but the passive damping method is applied in this paper [31,32].

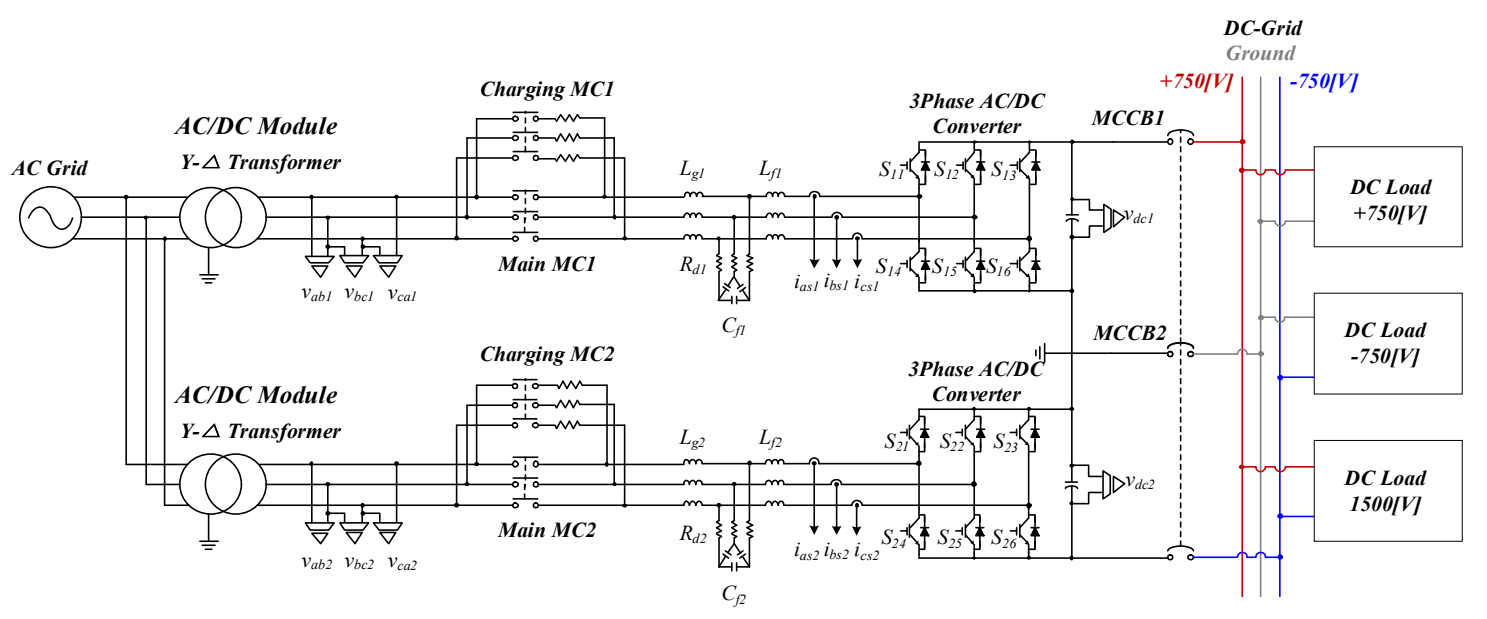

Figure 2. Proposed configuration of a bipolar low voltage DC (LVDC) distribution system.

The top power conversion module and the bottom power conversion module control the output voltage $+750 \mathrm{~V}_{\mathrm{dc}}$ as separate power converters, respectively. The voltage Vdc1 of the upper capacitor and the voltage Vdc2 of the lower capacitor do not affect each other because the closed circuit is not 
formed, even if the bipolar load power is unbalanced. Therefore, the simplicity of the control and the reliability of the system can be improved since the balancing control using a neutral point is no longer necessary. Due to various voltages, it can be used according to the purpose and the capacity of the load.

AC distribution systems, allow up to a voltage variation of $\pm 10 \%$ from the reference voltage as a steady voltage, thus AC loads have robust characteristics against voltage fluctuations. However, the loads that are in the next-generation DC distribution systems are mostly composed of electronic loads sensitive to voltage fluctuations. Therefore, a new compensation technique is proposed for transient conditions in DC distribution systems to satisfy high power quality and stable voltage regulation for sensitive loads when considering the distribution systems that are connected with irregular renewable energy generation.

\subsection{Relation to Transient State and Voltage Vector}

In the AC/DC PCS, a PI voltage controller for DC link voltage control and a PI current controller for AC current control are used in series. The voltage of the DC link is indirectly controlled by controlling the 3-phase AC current and the power factor. The AC/DC PCS has an output dc link consisting of a capacitor, which causes an instantaneous undershoot due to $\mathrm{d} v / \mathrm{d} t$ of the $\mathrm{dc}$ link capacitor when the load is connected or the power generation of the distributed power supply suddenly decreases. On the contrary, an overshoot occurs on the DC distribution voltage instantaneously when the connection of a load using a constant power is suddenly disconnected or when the distributed power has to regenerate the generated power to the system due to an instantaneous increase of power generation.

As a method of minimizing the overshoot and undershoot, the transient response of the converter can be improved through the power feedforward control by receiving information of load and renewable energy generation power in real time. However, it is practically impossible to collect the information of the power input/output status of all the loads that are connected to the power distribution through such communication. Therefore, compensation for this transient condition must be made in an AC/DC PCS that forms a DC distribution.

The voltage vector of AC/DC PCS using SVPWM is affected by fluctuations in the DC distribution voltage (i.e., DC link voltage of the AC/DC PCS) in this transient state when the converter controls the AC side pulse width modulation (PWM) output. Therefore, voltage vectors of SVPWM should be analyzed in both the steady state and transient state.

\subsection{Space Vector Pulse Width Modulation (SVPWM) in Steady State}

The vector diagram of SVPWM in steady state is represented, as shown in Figure 3 . The $V_{1}$ to $V_{6}$ are output voltage vectors from AC/DC PCS. These vectors are each phase-shifted by $60^{\circ}$ and their magnitude is proportional to the DC link voltage of the converter to $2 V_{d c} / 3$.

The $V_{0}$ and $V_{7}$ vectors are referred to as zero voltage vectors because no actual voltage is output to the AC side load. The maximum output voltage of an inverter that can be linearly output in the SVPWM is equal to the radius of the circle that is inscribed in hexagon of Figure 3 [18-21]. 


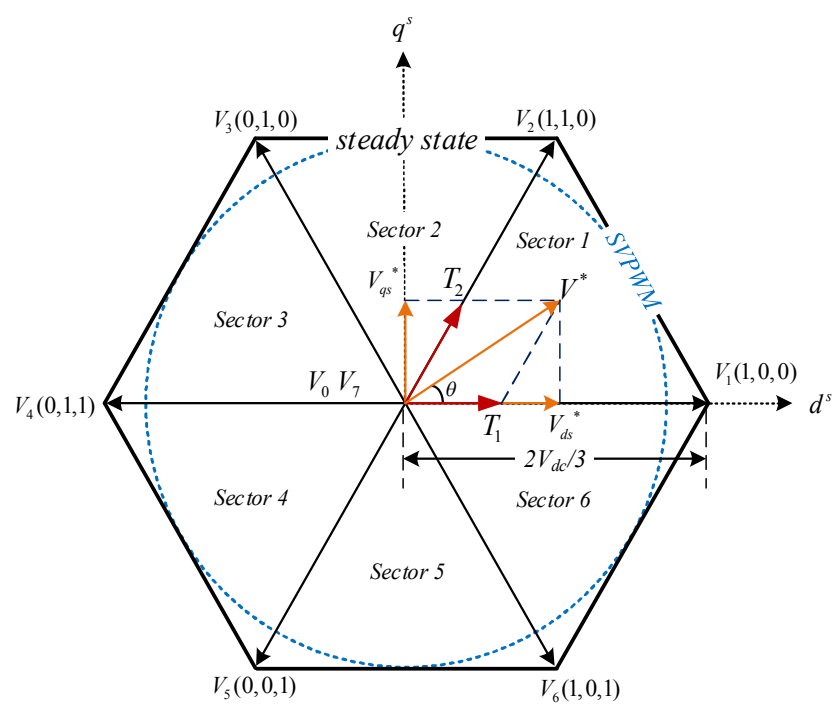

Figure 3. Space voltage vector diagram at steady state.

The SVPWM selects two adjacent valid vectors on the space vector in order to generate the command voltage and calculates the time each vector is applied. The applying time of two valid vectors are calculated, as shown in Equations (1)-(3) using the switching period.

$$
\begin{gathered}
T_{1}=\frac{T_{s}\left|V^{*}\right|}{2 V_{d c} / 3} \cdot \frac{\sin (\pi / 3-\alpha)}{\sin (\pi / 3)} \\
T_{2}=\frac{T_{s}\left|V^{*}\right|}{2 V_{d c} / 3} \cdot \frac{\sin (\alpha)}{\sin (\pi / 3)} \\
T_{0}=T_{s}-\left(T_{1}+T_{2}\right)
\end{gathered}
$$

The time when two vectors adjacent to the command voltage vector are applied by the Equations (1)-(3) is proportional to the maximum voltage $\left(=2 V_{d c} / 3\right)$ that each vector can output. However, when $T_{1}, T_{2}$, and $T_{0}$ are calculated to follow the reference voltage, according to Equations (1)-(3), if the voltage of the DC link changes, then $T_{1}, T_{2}$, and $T_{0}$ also change. $T_{1}, T_{2}$, and $T_{0}$ are changed when transient voltage occurs in the DC link of the AC/DC PCS (i.e., the DC distribution voltage). If the voltage of the DC link increases, $T_{1}, T_{2}$, and $T_{0}$ must be calculated as smaller than the steady state in order to reach the reference voltage again for a fast response. When the voltage of the DC link decreases, $T_{1}, T_{2}, T_{0}$ must be increased when compared to the steady state. Therefore, the time to apply the adjacent vector in the currently used SVPWM should be changed according to the voltage change in the DC-link.

\subsection{SVPWM Analysis in Transient State}

In the steady state, the maximum value of $\mathrm{V}_{1}-\mathrm{V}_{6}$ is fixed at $2 V_{d c} / 3$. However, when an overshoot or undershoot occurs in the output voltage, as shown in Figure 4 , the maximum voltage that can be output by the six vectors changes. When an overshoot occurs, the maximum output voltage of each vector increases by $v_{\text {overshoot }}$ and decreases by $v_{\text {undershoot }}$ when an undershoot occurs. This relationship is shown in the following equations.

$$
\begin{aligned}
& v_{\text {overshoot }}=v_{d c}-V_{d c}\left(v_{d c}>V_{d c}\right) \\
& v_{\text {undershoot }}=v_{d c}-V_{d c}\left(v_{d c}<V_{d c}\right) \\
& v_{\text {transient }}=v_{\text {overshoot }}+v_{\text {undershoot }}
\end{aligned}
$$


According to Equations (4)-(6), the maximum value of two adjacent vectors changes when an overshoot or undershoot occurs. Therefore, the switching time for generating the reference voltage should be changed as shown in Equations (7)-(9).

$$
\begin{gathered}
T_{1}=\frac{T_{s}\left|V^{*}\right|}{\frac{2}{3}\left(V_{d c}+v_{\text {transient }}\right)} \cdot \frac{\sin (\pi / 3-\alpha)}{\sin (\pi / 3)} \\
T_{2}=\frac{T_{s}\left|V^{*}\right|}{\frac{2}{3}\left(V_{d c}+v_{\text {transient }}\right)} \cdot \frac{\sin (\alpha)}{\sin (\pi / 3)} \\
T_{0}=T_{s}-\left(T_{1}+T_{2}\right)
\end{gathered}
$$

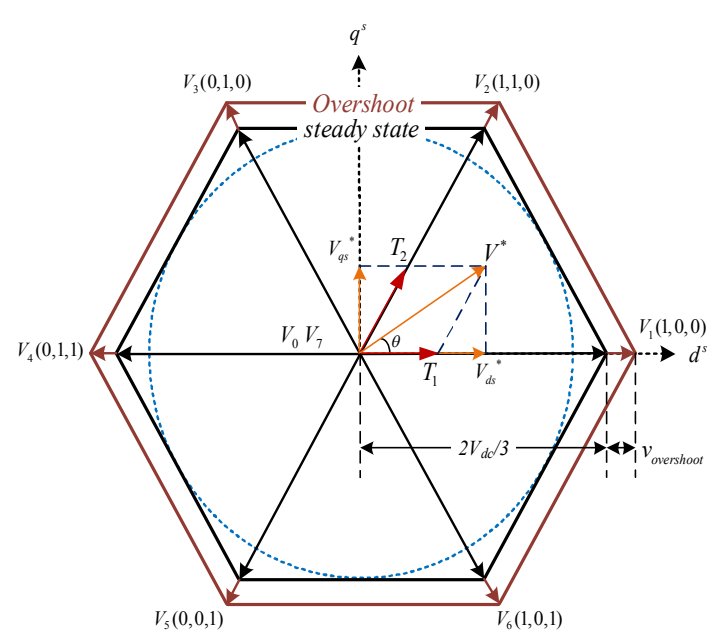

(a)

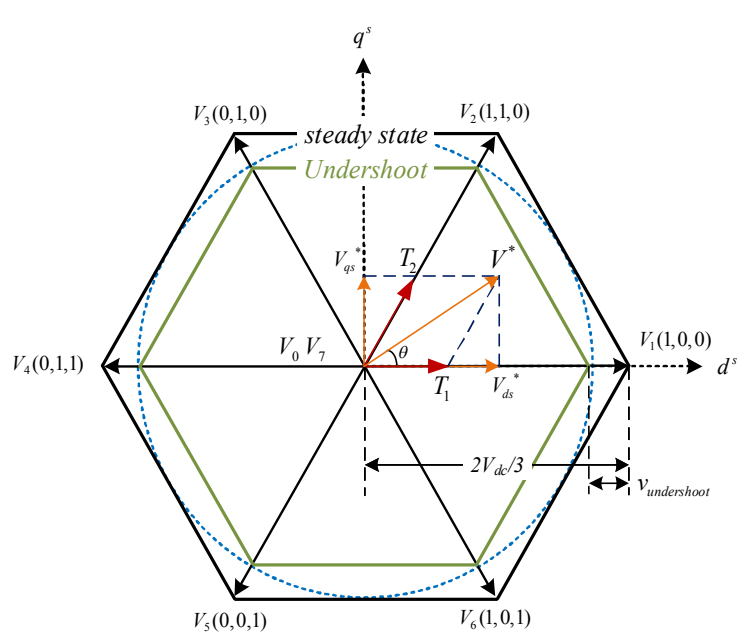

(b)

Figure 4. Changing of space voltage vector under transient state in (a) overshoot and (b) undershoot.

Therefore, the switching time calculated from Equations (1)-(3) and (7)-(9) has an error. The error in Sector 1 is shown in Equations (10) and (11).

$$
\begin{aligned}
& T_{1 \_ \text {err }}=T_{1}-T_{1 \_ \text {transient }}=-\left(T_{a s}-T_{b s}\right)\left(\frac{T_{s}}{v_{\text {transient }}}\right) \\
& T_{2 \_ \text {err }}=T_{2}-T_{2 \_ \text {transient }}=-\left(T_{b s}-T_{c s}\right)\left(\frac{T_{S}}{v_{\text {transient }}}\right)
\end{aligned}
$$

When the switching time is calculated as in the conventional method in Equations (1)-(3), the response characteristic due to the error is worsened when the transient state occurs. Therefore, it is desired to minimize this error by improving the transient response characteristics.

\subsection{Feedforward Compensation Method of Output Voltage}

The output of SVPWM is compared with the carrier wave in order to determine the switching pattern. The $y$-axis of the carrier wave refers to the voltage of the output capacitor $\left(=V_{d c}\right)$. Therefore, when an overshoot or undershoot occurs, the maximum output value of each vector changes in the space voltage vector diagram, so that an error occurs in the output voltage of the three-phase inverter, according to Equations (1)-(11).

The relation between switching frequency and carrier waveform in a micro controller unit (MCU) is shown in Figure 5. Generally, a method of changing the value (y-axis) of the carrier waveform is used to compensate for the error. However, when generating the carrier waveform in the MCU, 
the slope of the carrier waveform is fixed according to the dividing ratio of the MCU. Therefore, if the maximum size (y-axis) of the carrier waveform changes, the switching period changes as well. According to Equations (1)-(3) and (7)-(9), the switching time is affected by one period $\left(=T_{s}\right)$ of the carrier frequency, so compensation using the carrier waveform cannot be accomplished at the same switching frequency. The switching frequency is changed if the conventional compensation method is used when an overshoot or undershoot occurs, which aggravates the total harmonic distortion (THD) characteristic of the ac side current.

Therefore, a feedforward compensation method for changing the reference voltage is proposed, as shown in Figure 6, without changing the carrier wave (i.e., a fixed switching frequency). The space voltage vector diagram of the proposed output voltage compensation method in Figure $6 \mathrm{~b}$ is illustrated, as shown in Figure 7. It shows the case in Sector 1 (In that time, $\left.v_{\text {compen }}^{*}=v_{\text {transient }}\right)$. The value of $T_{1}, T_{2}$, $T_{0}$ is changed because the value of the reference voltage is changed by the feed forward compensation.

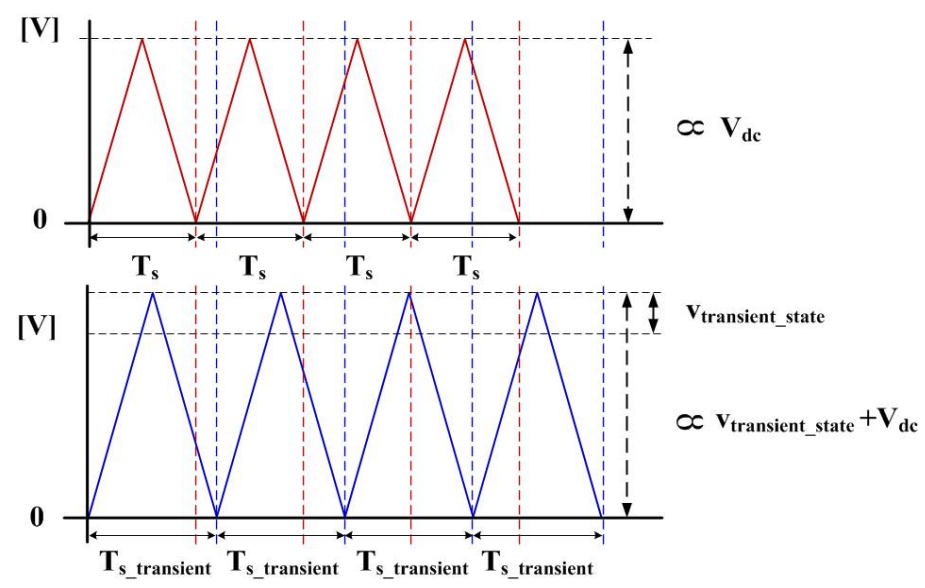

Figure 5. The relation between switching frequency and carrier wave in micro controller unit (MCU).

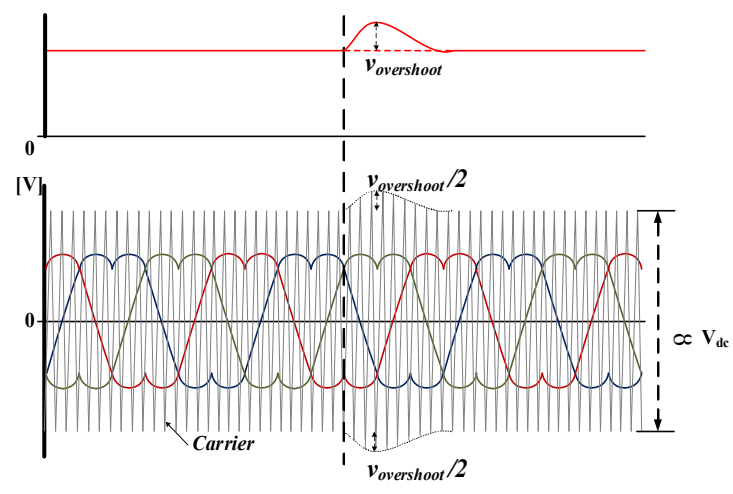

(a)

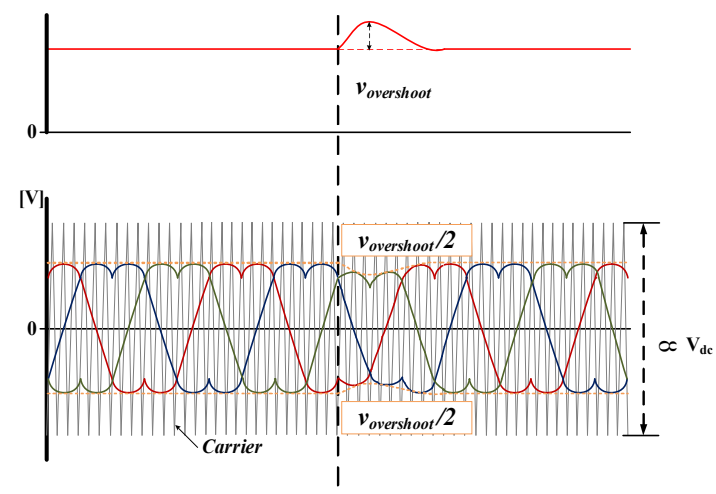

(b)

Figure 6. Two cases for the realization of the compensation value: (a) altered carrier wave: compensation value is applied in carrier wave; and (b) altered reference wave: compensation value is applied in reference wave.

Generally, control of a three-phase inverter (or converter) generates a switching pattern using the output of the current controller. However, the proposed control method measures variations in the output voltage that it is used to compensate for the reference voltage. The compensated value is then used in the voltage controller. However, the control period of the current controller is 10 times faster than the voltage controller because of the control frequency bandwidth, and the actual switching pattern is generated using the output of the current controller. Therefore, the current controller also 
must perform the same compensation in order to quickly respond in the frequent transient state. The current compensation value of the current controller is obtained by the voltage variation and the capacitance of the DC-link.

Figure 8 shows the overall control block diagram of the proposed system. The voltage and the current compensation values for transient state were applied to each controller. In Figure $8, \omega_{e}$ is voltage angular speed of AC side for VOC and phase locked loop (PLL). $\omega_{e 377}$ is fixed value of AC grid $(60 \mathrm{~Hz}) . i_{q}^{e}$ means active current and $i_{d}^{e}$ means reactive current. $v_{d}^{e}, v_{q}^{e}$ are the values synchronous $d-q$ transformed of input voltage. $v_{d c}$ is DC-link voltage, $i_{d c}$ is DC-link current. $R_{i}$ and $L_{i}$ are resistor and inductance of converter side, respectively.

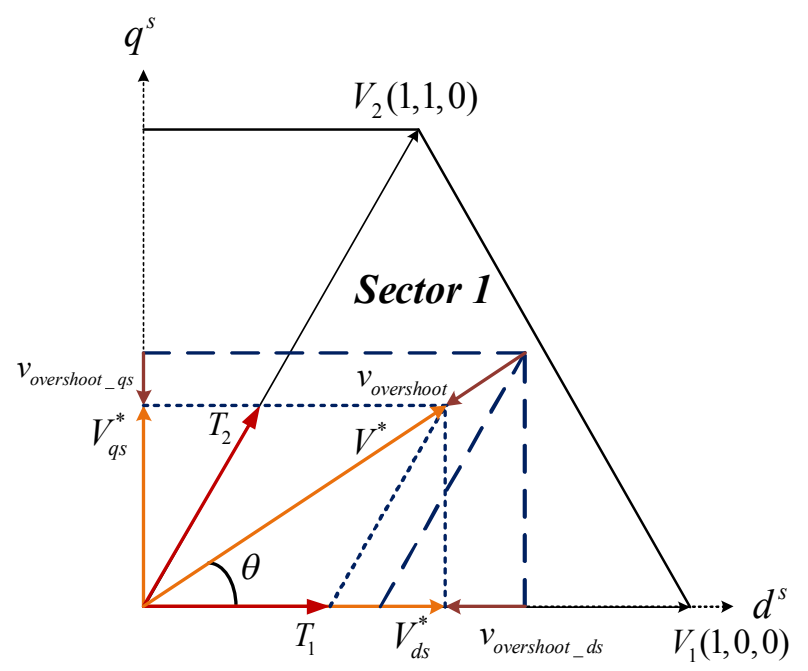

Figure 7. The altered reference voltage in Sector 1 of space vector pulse width modulation (SVPWM).

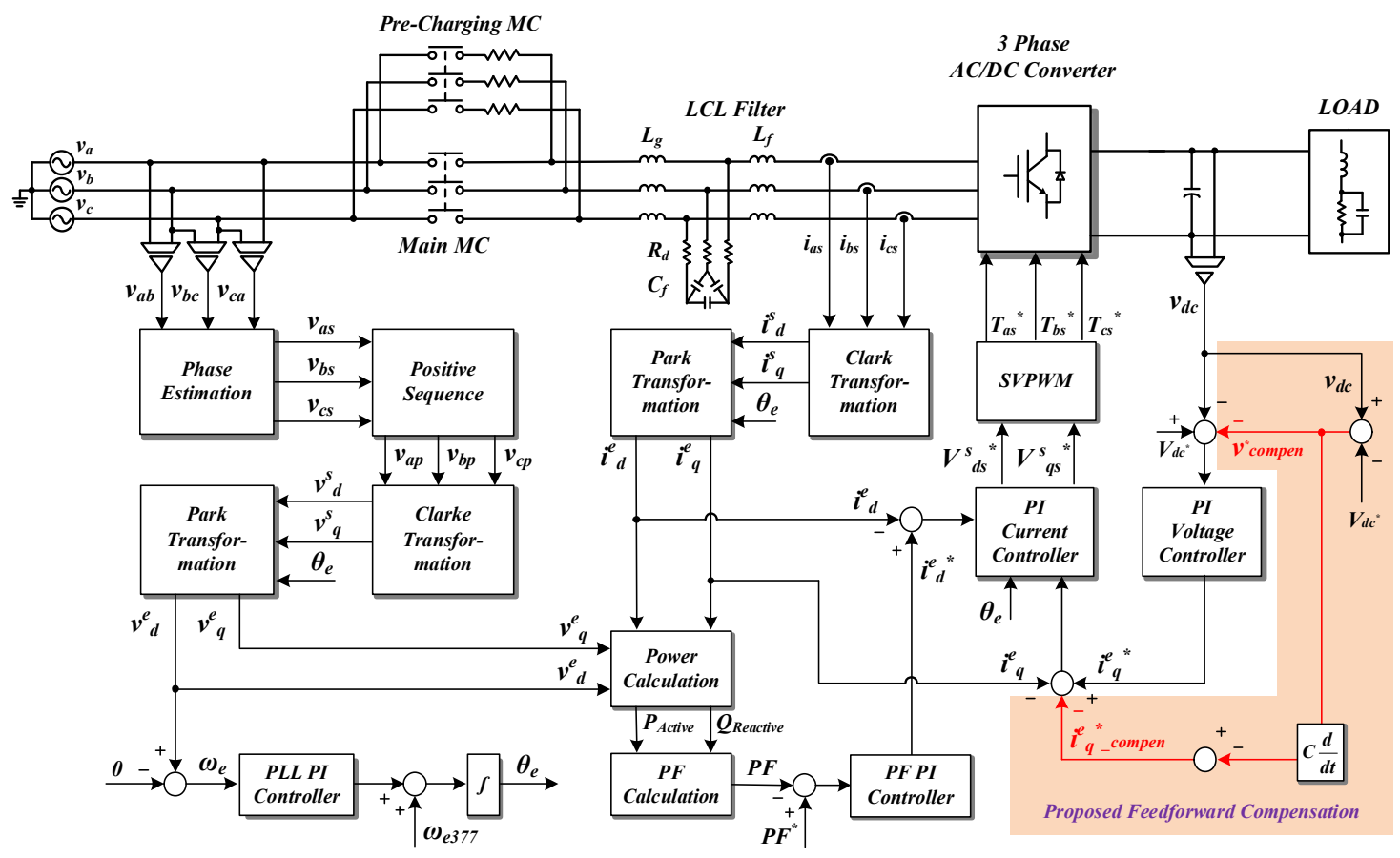

Figure 8. Overall control block diagram that applied the proposed compensation method of a module. 


\section{Simulation}

In order to verify the feasibility of the proposed feed forward compensation method, the simulation was performed using PSIM (PowerSIM, Rockville, MD, USA). The parameters of the system applied to the simulation are shown in Table 1.

Table 1. Parameter of proposed AC/DC pulse width modulation (PWM) converter.

\begin{tabular}{cccc}
\hline Parameters & Value & Unit \\
\hline Rated Power & 50 & $\mathrm{~kW}$ \\
\hline Input voltage $\left(V_{L L . r m s}\right)$ & 380 & $\mathrm{~V}_{\mathrm{rms}}$ \\
\hline & Source frequency & 60 & $\mathrm{~Hz}$ \\
\hline \multirow{3}{*}{ LCL Filter } & Switching frequency & 5 & $\mathrm{kHz}$ \\
\cline { 2 - 4 } & Source Side Inductance & 120 & $\mu \mathrm{H}$ \\
\cline { 2 - 4 } & Filter Capacitance & 50 & $\mu \mathrm{F}$ \\
\cline { 2 - 4 } & Converter Side Inductance & 500 & $\mu \mathrm{H}$ \\
\hline & DC-link Capacitance & 10,200 & $\mu \mathrm{F}$ \\
\hline & DC-link Voltage & 750 & $\mathrm{~V}_{\mathrm{dc}}$ \\
\hline
\end{tabular}

\section{Relation to Transient State and Voltage Vector}

Entire operation sequence is as shown in Figure 9. PCS starts operation at $0.2 \mathrm{~s}$ and the loads are connected to $0.4 \mathrm{~s}$ and $0.6 \mathrm{~s}$ in $25 \mathrm{~kW}$ increments. An AC voltage dip occurs at $0.8 \mathrm{~s}$ for the verified dynamic characteristic of the DC grid. The same value gains of PI voltage and current controller are applied to compare the proposed method to the conventional method. An AC voltage $70 \%$ dip ( 0.7 p.u) occurs, as shown in Figure 9.

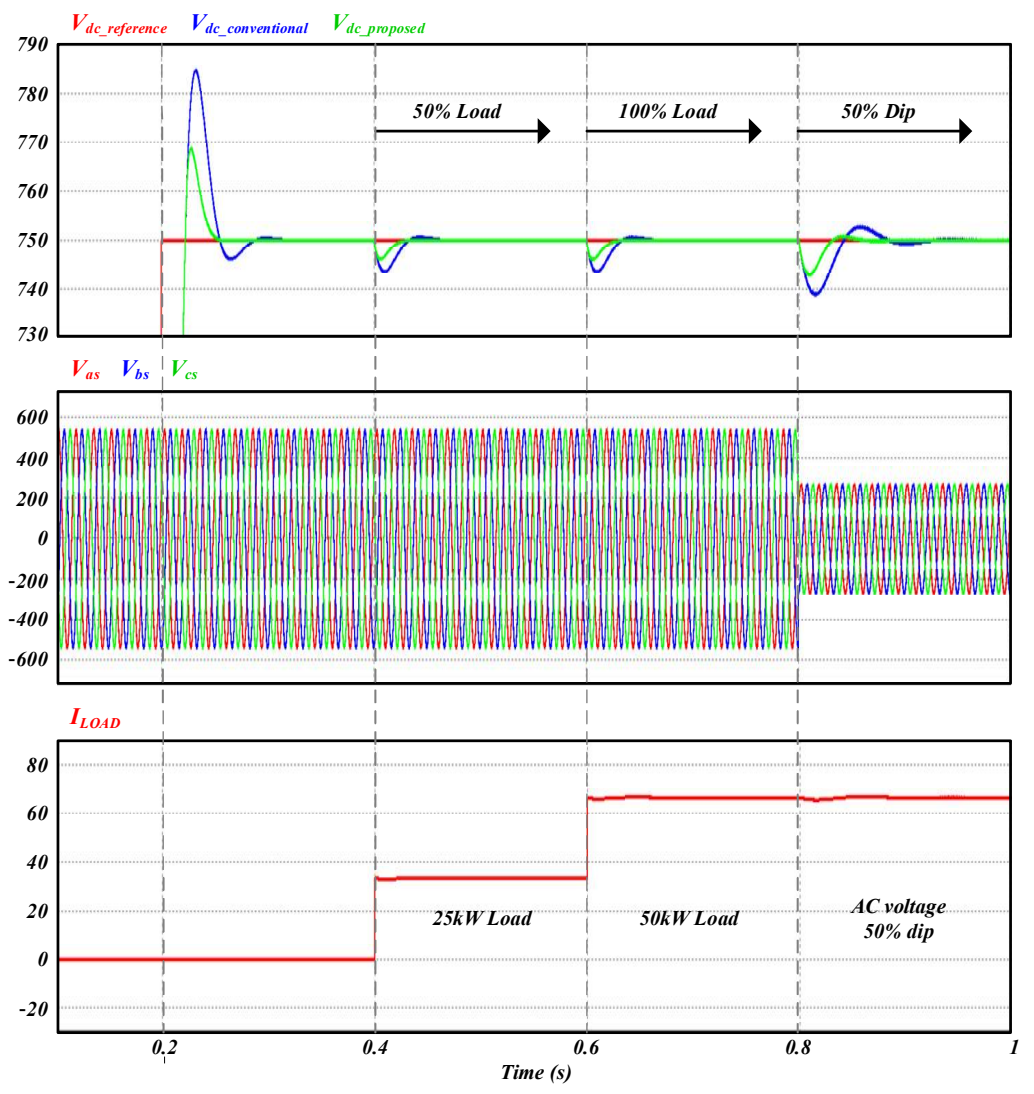

Figure 9. Comparison of the conventional method with the proposed control. 
The expanded waveform at the moment of applied load is as shown in Figure 10. When the $25 \mathrm{~kW}$ load is applied at $0.4 \mathrm{~s}$, an undershoot occurs in the DC grid voltage. This transient state (undershoot) cannot be avoided because the DC grid voltage is maintained by the capacitor. This undershoot becomes worse as a larger load is applied at a time.

When the conventional method is applied, about $6.4 \mathrm{~V}$ undershoot occurs. When the same load is applied with the proposed method, the magnitude of undershoot is reduced to about $3.9 \mathrm{~V}$, as shown in Figure 10a. The current control characteristic of the $d-q$ axis when the undershoot occurs is as shown in Figure 10b. In this paper, the proposed compensation method is not applied to the $d$-axis current controller. Thus, $d$-axis current has the same control characteristic. The current control characteristic of $q$-axis is improved by proposed compensation method. Therefore, the dynamic characteristic of DC voltage control is improved.

Figure 11 shows the dynamic characteristic of DC grid voltage on AC voltage $70 \%$ dip. In applying constant load, if an AC voltage dip occurs, DC grid voltage droops, as shown in Figure 11a. This situation is similar to when the load is applied on a DC grid. Therefore, this situation can be improved by the same compensation method.

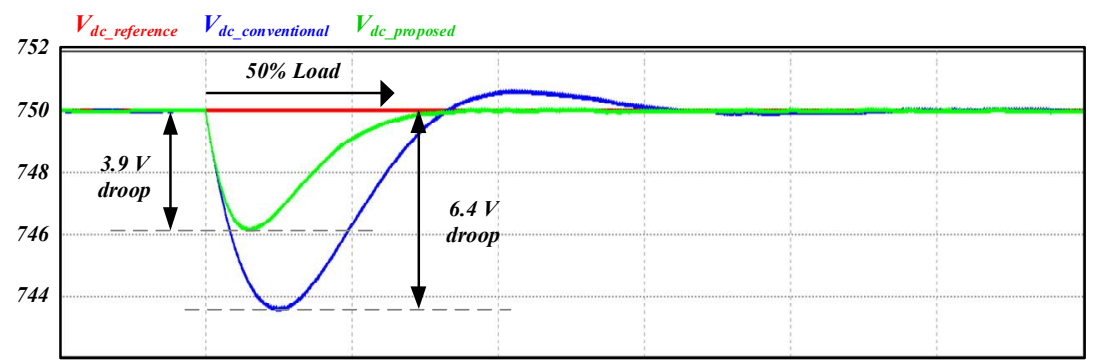

(a)

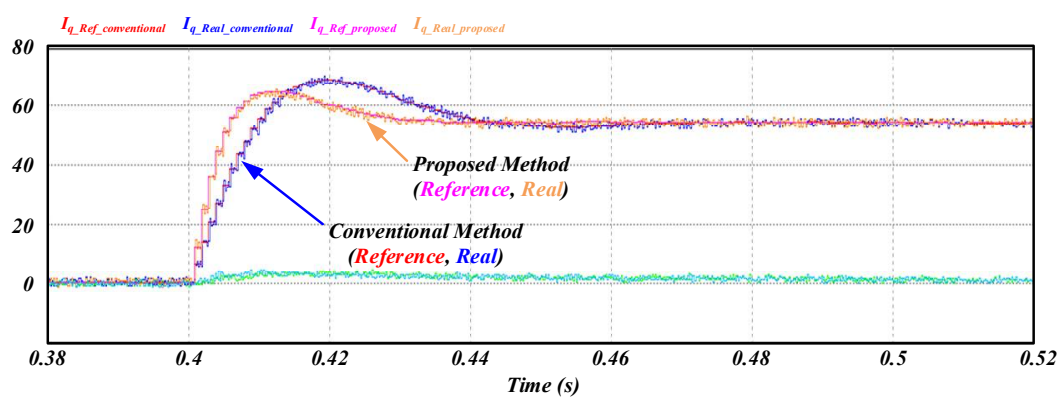

(b)

Figure 10. $\mathrm{V}_{\mathrm{dc}}$ and $q$-axis response characteristic (expanded). (a) Comparison of DC voltage dynamic responses at load connection; and (b) comparison $q$-axis current control characteristic.

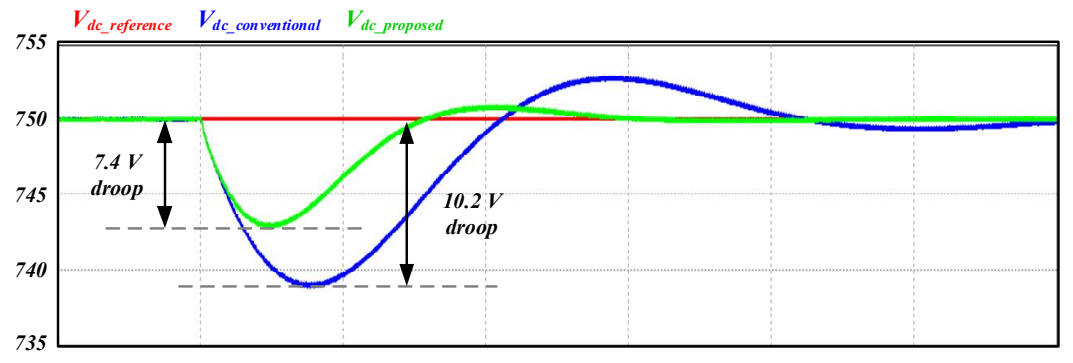

(a)

Figure 11. Cont. 


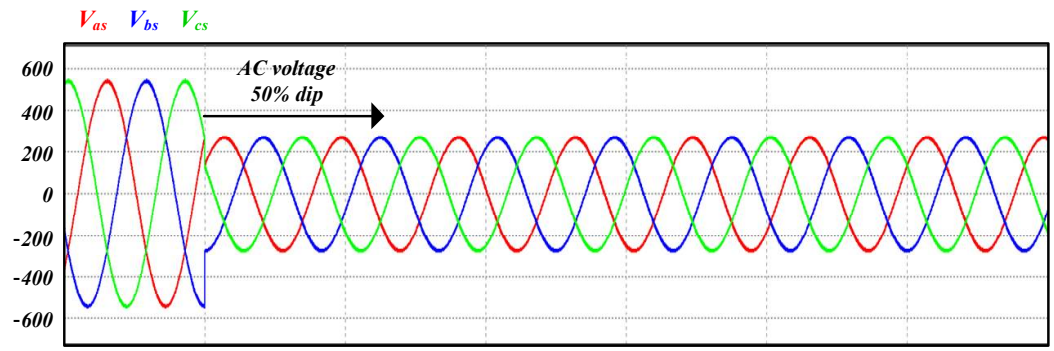

(b)

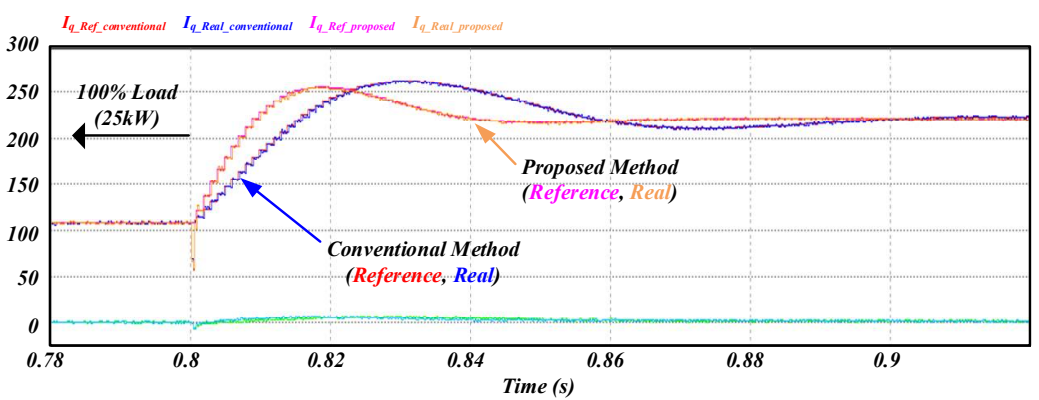

(c)

Figure 11. Dynamic response of DC grid voltage to AC voltage dip. (a) Comparison of DC voltage dynamic responses at voltage dip occurrence; (b) occurrence of AC voltage dip by 50\%; and (c) comparison $q$-axis current control characteristic.

\section{Experimental Result}

The hardware configuration for applying the proposed compensation method is as shown in Figure 12. In this paper, two AC/DC modules are applied. The capacity of each module is $50 \mathrm{~kW}$ and the switching frequency is set to $5 \mathrm{kHz}$. Each module controls the output voltage to $750 \mathrm{~V}_{\mathrm{dc}}$. The output of each module is configured in series. Therefore, the final distribution voltage is $\pm 750 \mathrm{~V}_{\mathrm{dc}}$. The loads that are connected to the proposed system can use various voltages.

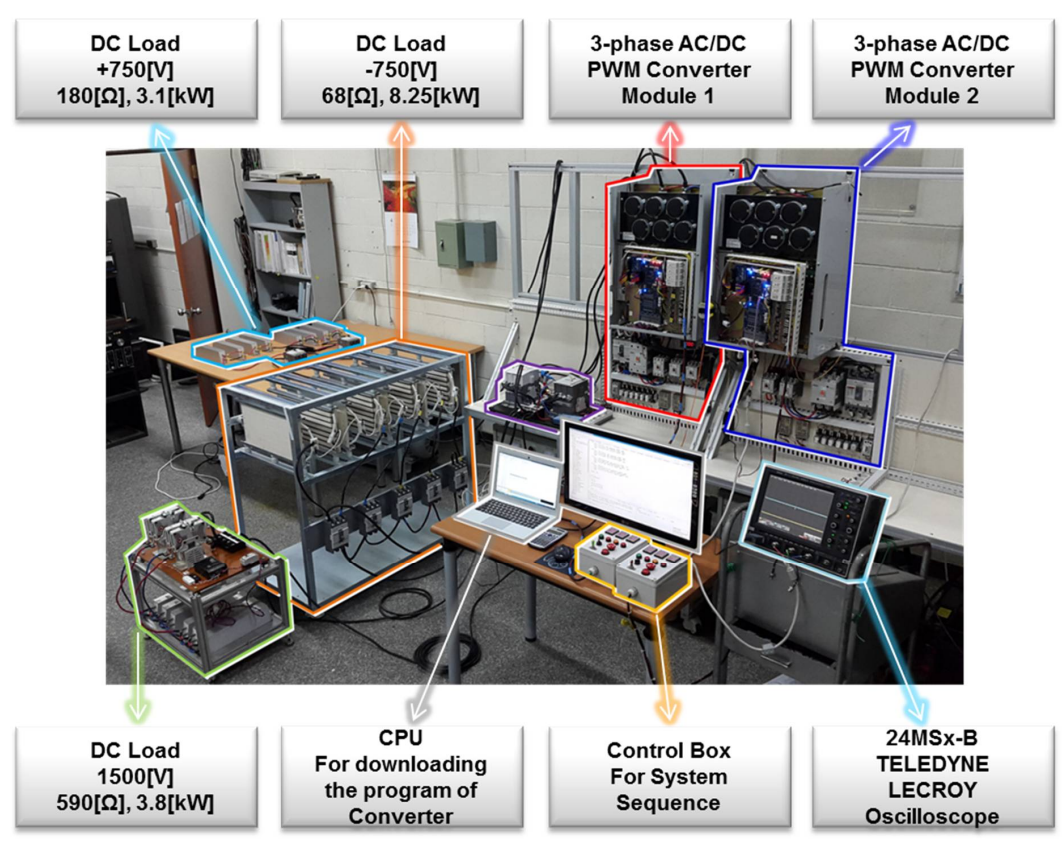

Figure 12. Hardware configuration. 
Figure 13 shows the experimental waveforms that are not applied to the proposed compensation method of 3-phase AC/DC PCS. A soft start is applied for minimizing exceed current inflow to capacitor during initial operation. $7 \mathrm{~kW}$ load is connected after output voltage is stable as $750 \mathrm{~V}_{\mathrm{dc}}$ (in $\pm 1 \%$ during $2 \mathrm{~s}$ ).

Figure $13 \mathrm{~b}$ shows the expanded waveform of the reference and feedback voltage of the voltage controller when the load is applied, as in Figure 13a. The reference voltage of the voltage controller is $750 \mathrm{~V}_{\mathrm{dc}}$ and it can be confirmed that the output voltage instantaneously decreases when the load is applied. Figure $13 \mathrm{c}$ shows the waveform of the $q$-axis reference and feedback of the current controller when the load is applied. At the moment of undershoot, the reference value of the current controller changes, but the output (=feedback) of the controller shows a slower response than the reference. Since the current controller and the voltage controller are operated separately and the actual switching waveform is generated using the output of the current controller, the two controllers must each be compensated for, respectively. Figure 13d shows the expanded waveform of the output voltage of the 3-phase AC/DC PCS in Figure 13a. When the load is applied, it can be confirmed that an undershoot of about $8.9 \mathrm{~V}$ occurs for $136 \mathrm{~ms}$.

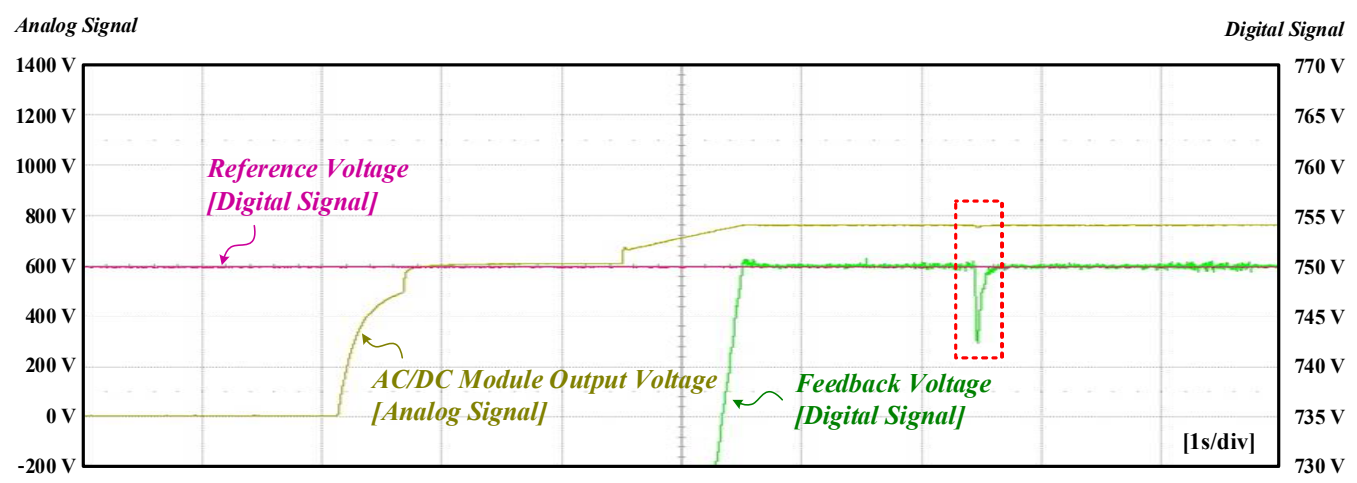

(a)

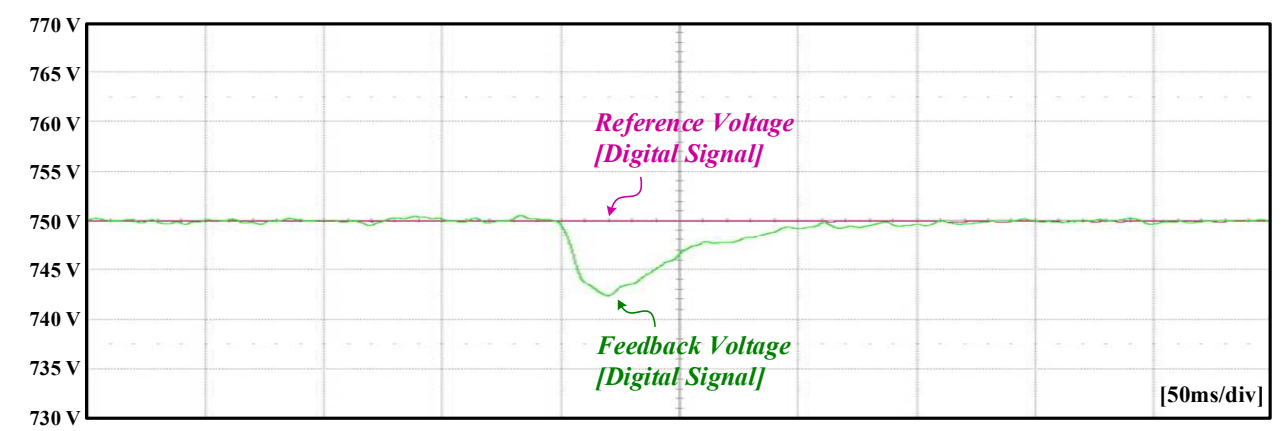

(b)

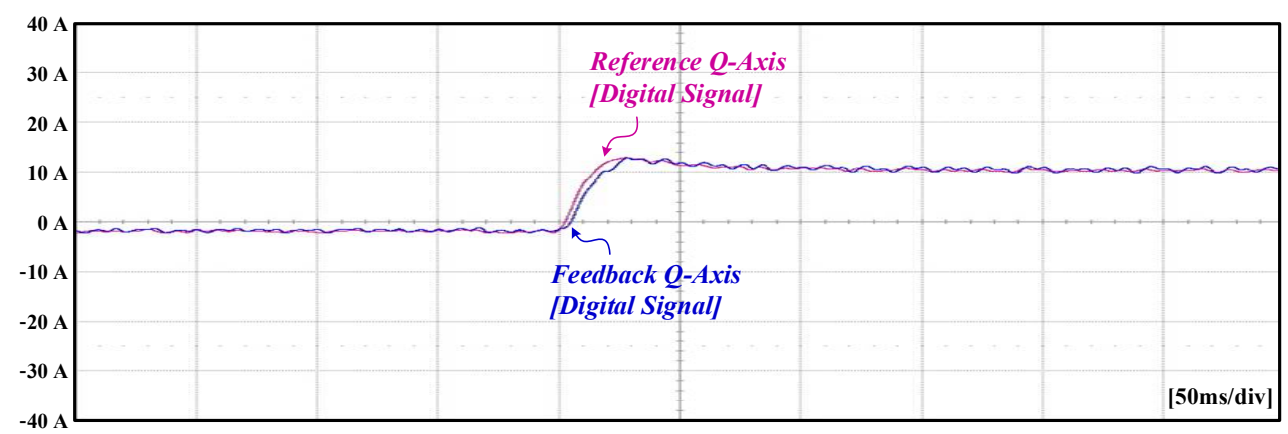

(c)

Figure 13. Cont. 


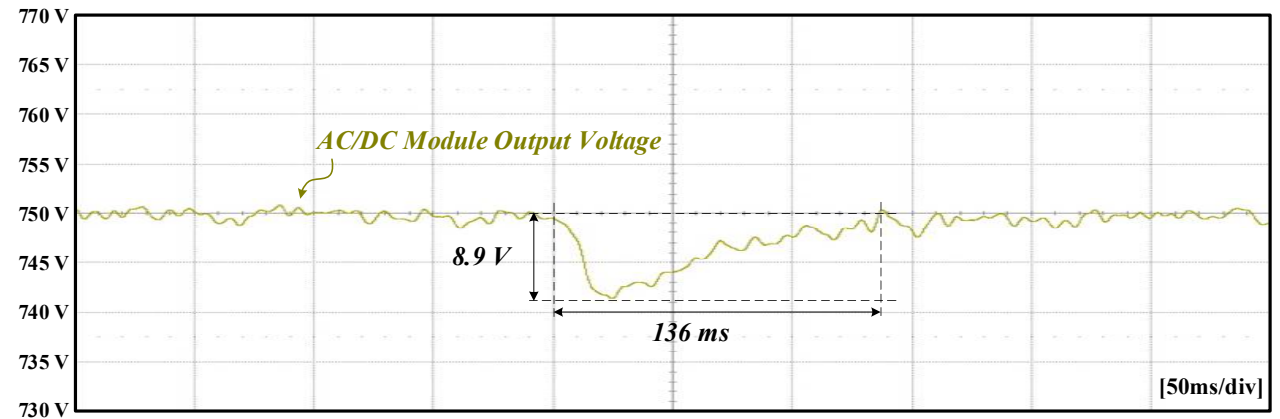

(d)

Figure 13. Experimental waveforms without the proposed method. (a) Reference and real voltage; (b) reference and real voltage of DC Bus (expanded); (c) reference and real $q$-axis current in synchronous frame; and (d) output voltage of module 1 (expanded).

Figure 14 shows the experimental waveform of a 3-phase AC/DC PCS using the proposed output voltage feed forward compensation method. Experiments were carried out under the same conditions, as in Figure 13.

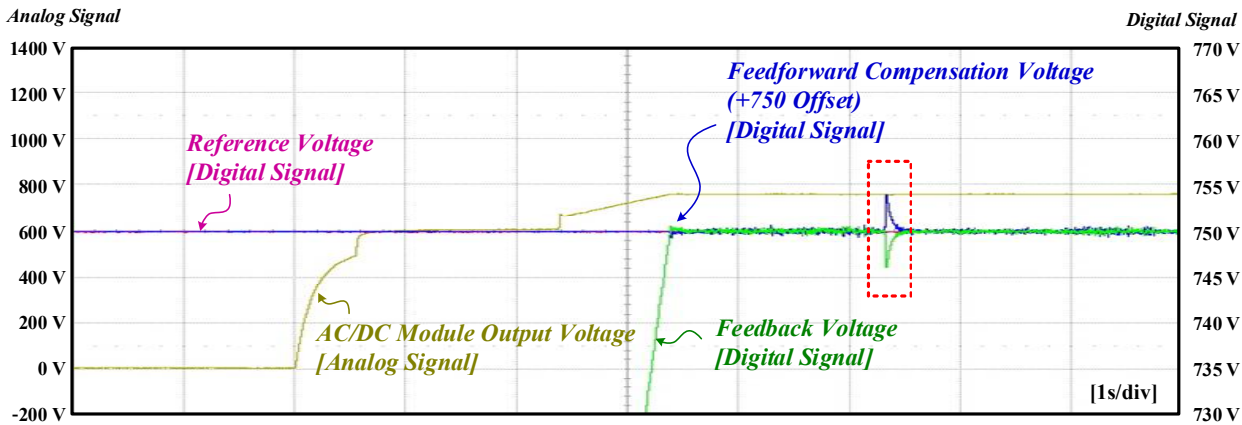

(a)

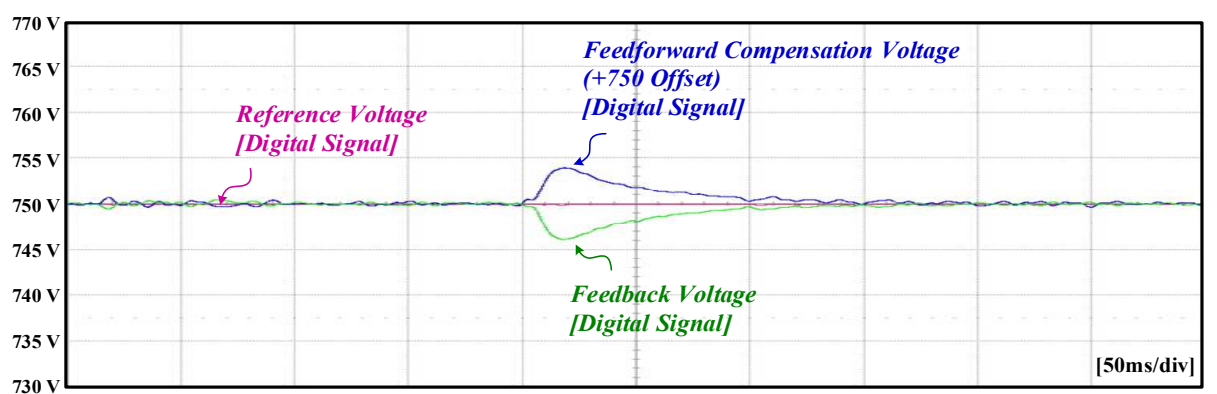

(b)

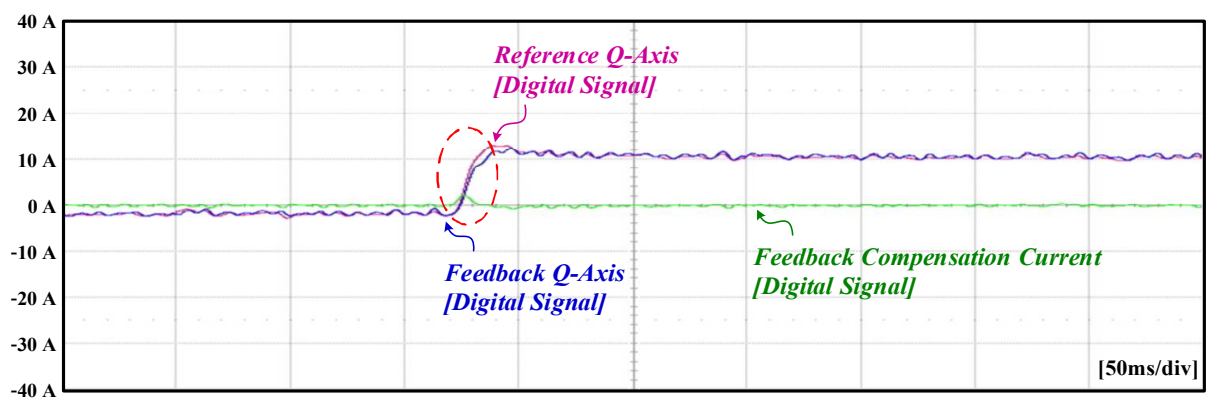

(c)

Figure 14. Cont. 


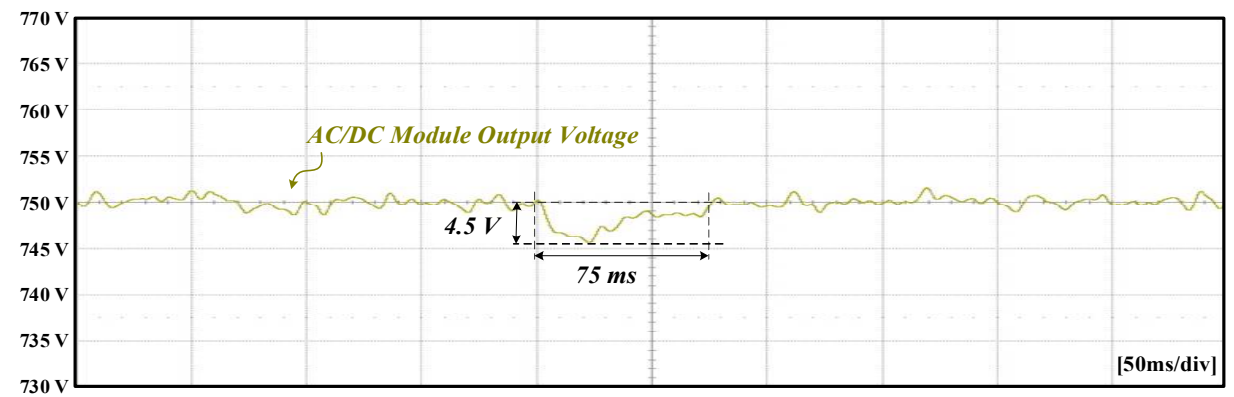

(d)

Figure 14. Experimental waveforms with the proposed method. (a) Reference and real voltage; (b) reference and real voltage of DC Bus (expanded); (c) reference and real $q$-axis current in synchronous frame; and (d) output voltage of module 1 (expanded).

Figure $14 \mathrm{~b}$ shows the output of the voltage controller using the proposed compensation method when the load is applied. The undershoot is reduced when compared to that shown in Figure 13, because the reference voltage of the voltage controller is $750 \mathrm{~V}_{\mathrm{dc}}$ and the forward compensation value is applied when the load is applied. Figure 14c shows the output of the current controller using the compensation method. The response characteristic is improved in the section where the voltage variation occurs by the compensation to current controller based on Figure 8 when overshoot (or undershoot) occurs as compared to the results in Figure 13c. Figure 14d shows the output voltage of a three-phase AC/DC PWM converter. When the load was applied, about a $4.5 \mathrm{~V}$ undershoot occurred for $75 \mathrm{~ms}$. When the proposed feed forward compensation method is applied, the magnitude of undershoot is reduced by $50 \%$ and the response is improved by $45 \%$.

\section{Conclusions}

In this paper, a new feed forward compensation method is proposed to improve the transient state response for the PCS configuring a DC distribution network in the DC distribution system. The degradation cause of the transient response is analyzed when SVPWM is used, and the feed forward compensation method is proposed to improve the response characteristic. The proposed method is investigated in order to solve the problems to be applied to the MCU, and a solution for this problem is suggested. The proposed method is applied to the bipolar low voltage DC (LVDC) system. It is also confirmed that the stability of the system is improved when the proposed method is applied through a modeling of the system. Simulation and experimentation were carried out by applying the proposed compensation method and the feasibility of the proposed method was verified. When the proposed method is applied to the LVDC system connected with various loads and renewable energy, it is possible to construct a robust distribution with an improved transient response characteristic.

Author Contributions: S.-J.H. designed the experiment; S.-J.H., S.-W.H. and K.-M.K. performed the experiment; S.-J.H., K.-M.K. and J.-H.L. analyzed the theory. S.-J.H. wrote the manuscript. J.-H.L. and C.-Y.W. participated in research plan development and revised the manuscript. All authors have contributed to the manuscript.

Acknowledgments: This work was supported by "Human Resources Program in Energy Technology" of the Korea Institute of Energy Technology Evaluation and Planning (KETEP), granted financial resource from the Ministry of Trade, Industry \& Energy, Korea (No. 20164030200980).

Conflicts of Interest: The authors declare no conflict of interest.

\section{References}

1. Wu, T.F.; Chang, C.H.; Lin, L.C.; Yu, G.R.; Chang, Y.R. DC-bus voltage control with a three-phase bidirectional inverter for DC distribution systems. IEEE Trans. Power Electron. 2013, 28, 1890-1899. [CrossRef]

2. Yu, X.; She, X.; Zhou, X.; Huang, A.Q. Power Management for DC Microgrid Enabled by Solid-State Transformer. IEEE Trans. Smart Grid 2014, 5, 954-965. [CrossRef] 
3. Mackay, L.; Blij, N.H.V.D.; Ramirez-Elizondo, L.; Bauer, P. Towards the Universal DC Distribution System. Electr. Power Compon. Syst. 2017, 45, 1032-1042. [CrossRef]

4. Kim, H.S.; Ryu, M.H.; Baek, J.W.; Jung, J.H. High-Efficiency Isolated Bidirectional AC-DC Converter for a DC Distribution System. IEEE Trans. Power Electron. 2013, 28, 1642-1654. [CrossRef]

5. Sechilariu, M.; Wang, B.; Locment, F. Building integrated photovoltaic system with energy storage and smart grid communication. IEEE Trans. Ind. Electron. 2013, 60, 1607-1618. [CrossRef]

6. Dragicevic, T.; Lu, X.; Vasquez, J.C.; Guerrero, J.M. DC Microgrids-Part II: A Review of Power Architectures, Applications, and Standardization Issues. IEEE Trans. Power Electron. 2016, 31, 3528-3549. [CrossRef]

7. Whaite, S.; Grainger, B.; Kwasinski, A. Power Quality in DC Power Distribution Systems and Microgrids. Energies 2015, 8, 4378-4399. [CrossRef]

8. Ryu, M.H.; Kim, H.S.; Baek, J.W.; Kim, H.G.; Jung, J.H. Effective test bed of 380-V DC distribution system using isolated power converters. IEEE Trans. Ind. Electron. 2015, 62, 4525-4536. [CrossRef]

9. Shin, S.C.; Lee, H.J.; Kim, Y.H.; Lee, J.H.; Won, C.Y. Transient response improvement at startup of a threephase $\mathrm{AC} / \mathrm{DC}$ converter for a DC distribution system in commercial facilities. IEEE Trans. Power Electron. 2014, 29, 6742-6753. [CrossRef]

10. Chen, W.; Dai, W.; Wang, Z.; Zhang, G.; Yan, Y.; Xia, C. Optimal space vector pulse width modulation strategy of neutral point clamped three-level inverter for output current ripple reduction. IET Power Electron. 2017, 10, 1638-1646. [CrossRef]

11. Hintz, A.; Prasanna, U.R.; Rajashekara, K. Comparative Study of the Three-Phase Grid-Connected Inverter Sharing Unbalanced Three-Phase and/or Single-Phase systems. IEEE Trans. Ind. Appl. 2016, 52, 5156-5164. [CrossRef]

12. Huang, Y.; Wang, D.; Shang, L.; Zhu, G.; Tang, H.; Li, Y. Modeling and Stability Analysis of DC-Link Voltage Control in Multi-VSCs with Integrated to Weak Grid. IEEE Trans. Energy Convers. 2017, 32, 1127-1138. [CrossRef]

13. Chen, W.W.; Zane, R.; Corradini, L. Isolated Bidirectional Grid-Tied Three-Phase AC-DC Power Conversion Using Series-Resonant Converter Modules and a Three-Phase Unfolder. IEEE Trans. Power Electron. 2017, 32, 9001-9012. [CrossRef]

14. Jamma, M.; Barara, M.; Akherraz, M.; Enache, B.A. Voltage oriented control of three-phase PWM rectifier using space vector modulation and input output feedback linearization theory. In Proceedings of the 8th International Conference on Electronics, Computers and Artificial Intelligence (ECAI), Ploiesti, Romania, 30 June-2 July 2016; pp. 1-8.

15. Kadri, R.; Gaubert, J.P.; Champenois, G. An improved maximum power point tracking for photovoltaic grid-connected inverter based on voltage-oriented control. IEEE Trans. Ind. Electron. 2011, 58, 66-75. [CrossRef]

16. Trinh, Q.N.; Wang, P.; Choo, F.H. An Improved Control Strategy of Three-Phase PWM Rectifiers under Input Voltage Distortions and DC-Offset Measurement Errors. IEEE J. Emerg. Sel. Top. Power Electron. 2017, 5, 1164-1176. [CrossRef]

17. Jung, T.; Gwon, G.; Kim, C.H.; Han, J.; Oh, Y.; Noh, C.H. Voltage Regulation Method for Voltage Drop Compensation and Unbalance Reduction in Bipolar Low-Voltage DC Distribution System. IEEE Trans. Power Deliv. 2018, 33, 141-149. [CrossRef]

18. Choe, S.; Son, Y.K.; Sul, S.K. Control and Analysis of Engine Governor for Improved Stability of DC Microgrid against Load Disturbance. IEEE J. Emerg. Sel. Top. Power Electron. 2016, 4, 1247-1258. [CrossRef]

19. Kakigano, H.; Miura, Y.; Ise, T. Low-Voltage Bipolar-Type DC Microgrid for Super High Quality Distribution. IEEE Trans. Power Electron. 2010, 25, 3066-3075. [CrossRef]

20. Huang, M.; Peng, Y.; Chi, K.T.; Liu, Y.; Sun, J.; Zha, X. Bifurcation and Large-Signal Stability Analysis of Three-Phase Voltage Source Converter Under Grid Voltage Dips. IEEE Trans. Power Electron. 2017, 32, 8868-8879. [CrossRef]

21. Bongiorno, M.; Svensson, J. Voltage dip mitigation using shunt connected voltage source converter. IEEE Trans. Power Electron. 2007, 22, 1867-1874. [CrossRef]

22. Davari, M.; Mohamed, Y.A.R.I. Dynamics and robust control of a grid-connected VSC in multiterminal DC grids considering the instantaneous power of DC-and AC-side filters and DC grid uncertainty. IEEE Trans. Power Electron. 2016, 31, 1942-1958. [CrossRef] 
23. Davari, M.; Mohamed, Y.A.R.I. Robust Vector Control of a Very Weak-Grid-Connected Voltage-Source Converter Considering the Phase-Locked Loop Dynamics. IEEE Trans. Power Electron. 2017, 32, 977-994. [CrossRef]

24. Davari, M.; Mohamed, Y.A.R.I. Robust multi-objective control of VSC-based DC-voltage power port in hybrid AC/DC multi-terminal microgrids. IEEE Trans. Smart Grids 2013, 4, 1597-1612. [CrossRef]

25. Nasirian, V.; Davoudi, A.; Lewis, F.L.; Guerrero, J.M. Distributed Adaptive Droop Control for DC Distribution Systems. IEEE Trans. Energy Convers. 2014, 29, 944-956. [CrossRef]

26. Tahim, A.P.N.; Pagano, D.J.; Lenz, E.; Stramosk, V. Modeling and stability analysis of islanded DC microgrids under droop control. IEEE Trans. Power Electron. 2015, 30, 4597-4607. [CrossRef]

27. Lu, X.; Guerrero, J.M.; Sun, K.; Vasquez, J.C. An Improved Droop Control Method for DC Microgrids Based on Low Bandwidth Communication with DC Bus Voltage Restoration and Enhanced Current Sharing Accuracy. IEEE Trans. Power Electron. 2014, 29, 1800-1812. [CrossRef]

28. Federico, I.; Jose, E.; Luis, F. Master-slave DC droop control for paralleling auxiliary DC/DC converters in electric bus applications. IET Power Electron. 2017, 10, 1156-1164. [CrossRef]

29. Li, G.; Du, Z.; Shen, C.; Yuan, Z.; Wu, G. Coordinated Design of Droop Control in MTDC Grid Based on Model Predictive Control. IEEE Trans. Power Syst. 2018, 33, 2816-2828. [CrossRef]

30. Simes, M.G.; Farret, F.A. Designing Power Electronic Control Systems, 1st ed.; Wiley-IEEE Press: Hoboken, NJ, USA, 2017; ISBN 9781119058458.

31. Jayalath, S.; Hanif, M. Generalized LCL-Filter Design Algorithm for Grid-Connected Voltage-Source Inverter. IEEE Trans. Ind. Electron. 2017, 64, 1905-1915. [CrossRef]

32. Rockhill, A.A.; Liserre, M.; Teodorescu, R.; Rodriguez, P. Grid-Filter Design for a Multimegawatt Medium-Voltage Voltage-Source Inverter. IEEE Trans. Ind. Electron. 2011, 58, 1205-1217. [CrossRef]

(C) 2018 by the authors. Licensee MDPI, Basel, Switzerland. This article is an open access article distributed under the terms and conditions of the Creative Commons Attribution (CC BY) license (http:/ / creativecommons.org/licenses/by/4.0/). 